\title{
Effects of the linagliptin, dipeptidyl peptidase-4 inhibitor, on bone fragility induced by type 2 diabetes mellitus in obese mice
}

\author{
Junkichi Kanda ${ }^{1}$, Megumi Furukawa ${ }^{2}$, Nobuo Izumo ${ }^{2}$, Taketoshi Shimakura ${ }^{3}$, \\ Noriaki Yamamoto ${ }^{3,4}$, Hideaki E. Takahashi ${ }^{3}$, Hiroyuki Wakabayashi, ${ }^{1, *}$ \\ ${ }^{1}$ Department of Clinical Pharmacotherapy, Faculty of Pharmaceutical Sciences, Niigata University of Pharmacy and Applied Life Sciences, \\ Niigata, Japan; \\ ${ }^{2}$ General Health Medical Center, Yokohama University of Pharmacy, Yokohama, Japan; \\ ${ }^{3}$ Niigata Bone Science Institute, Niigata, Japan; \\ ${ }^{4}$ Division of Orthopedic Surgery, Niigata Rehabilitation Hospital, Niigata, Japan.
}

SUMMARY Recently, it has been suggested that glucose-dependent insulinotropic polypeptide (GIP) and glucagonlike peptide 1 (GLP-1), which play important roles in the homeostasis of glucose metabolism, could be involved in the regulation of bone metabolism. Inhibitors of dipeptidyl peptidase 4 (DPP-4), an enzyme that degrades GIP and GLP-1, are widely used clinically as a therapeutic agent for diabetes. However, the effects of DPP-4 inhibitors on bone metabolism remain unclear. In this study, we investigated the effects of linagliptin, a DPP-4 inhibitor, on bone fragility induced by type 2 diabetes mellitus (T2DM). Non-diabetic mice were used as controls, and T2DM mice were administered linagliptin orally on a daily basis for 12 weeks. In T2DM mice, decreased bone mineral density was observed in the lower limb bones along with low serum osteocalcin levels and high serum tartrate-resistant acid phosphatase$5 \mathrm{~b}$ (TRAP) levels. In contrast, the decreased serum osteocalcin levels and increased serum TRAP levels observed in T2DM mice were significantly suppressed after the administration of linagliptin 30 $\mathrm{mg} / \mathrm{kg}$. Bone histomorphometric analysis revealed a reduced osteoid volume and osteoblast surface with an increase in the eroded surface and number of osteoclasts in T2DM mice. This decreased bone formation and increased bone resorption observed in the T2DM mice were suppressed and trabecular bone volume increased following the administration of $30 \mathrm{mg} / \mathrm{kg}$ linagliptin. Collectively, these findings suggest that linagliptin may improve the microstructure of trabecular bone by inhibiting both a decrease in bone formation and an increase in bone resorption induced by T2DM.

Keywords Dipeptidyl peptidase-4 inhibitor, type 2 diabetes mellitus, bone fragility

\section{Introduction}

The bone is a metabolically active organ that undergoes continuous remodeling due to bone resorption by osteoclasts and bone formation by osteoblasts (1). Under healthy conditions, the balance between bone formation and bone resorption remains consistently uniform; thus, bone strength and bone density are maintained. Certain pathological states and drugs affect normal bone remodeling, which can induce skeletal disorders including osteopenia or osteoporosis (2).

Diabetes mellitus increases bone fragility by affecting bone metabolism, resulting in secondary osteoporosis, which increases the risk of fractures in patients (37). Furthermore, it has been revealed that several oral hypoglycemic agents affect bone metabolism (8). Longterm users of thiazolidinedione, an insulin sensitizer, have been reported to be at a significantly increased risk of fractures (9-12). Previous investigations have indicated that suppressed bone formation (13) and enhanced bone resorption (14) are the mechanisms underlying thiazolidine-induced bone fragility. Recently, it has been suggested that the incretins glucose-dependent insulinotropic polypeptide (GIP) and glucagon-like peptide 1 (GLP-1), which play an important role in the homeostasis of glucose metabolism, may be involved in the regulation of bone formation (15) and bone resorption (16). Currently, GLP-1 receptor agonists, which enhance incretin action, and inhibitors of dipeptidyl peptidase 4 (DPP-4), an enzyme that degrades GIP and GLP-1, are extensively used clinically as therapeutic agents in type 2 diabetes mellitus (T2DM). However, the effects of GLP-1 receptor agonists and DPP-4 inhibitors on bone metabolism have not been clarified. In this study, we 
investigated the effects of linagliptin, a DPP-4 inhibitor, on bone fragility induced by T2DM in obese mice.

\section{Materials and Methods}

\subsection{Animals}

Five-week-old male obese type 2 diabetic mice (BKS. Cg- $\left.+\operatorname{Lepr}^{d b} /+\operatorname{Lepr}^{d b} / J c l\right)$ and age-matched non-diabetic mice (BKS.Cg-m $+/+$ Lepr $^{d b} / J c l$ ) were purchased from CLEA Japan Inc. (Tokyo, Japan). The animals were housed at $22 \pm 2{ }^{\circ} \mathrm{C}$ and $55 \pm 5 \%$ humidity on a 12 -h light-dark cycle with ad libitum access to standard chow (MF; Oriental Yeast Co., Tokyo, Japan) and water. All procedures were approved by the Animal Research Committee of Niigata University of Pharmacy and Applied Life Sciences according to the Japanese Government Animal Protection and Management Law and the Japanese Government Notification on Feeding and Safekeeping of Animals.

\subsection{Drugs}

Commercially available linagliptin (Nippon Boehringer Ingelheim Co., Ltd., Tokyo, Japan) agents was obtained and suspended in $0.2 \%$ carboxymethylcellulose sodium solution (CMC-Na; Sigma-Aldrich, St. Louis, MO, USA).

\subsection{Experimental procedure}

The animals were randomly divided into four groups (10 animals per group): [1] non-diabetic mice (non$\mathrm{DM})$, [2] T2DM mice treated with vehicle $(0.2 \% \mathrm{CMC}$ $\mathrm{Na}$ (T2DM), [3] T2DM mice treated with $3 \mathrm{mg} / \mathrm{kg}$ linagliptin (Lina 3), and [4] T2DM mice treated with 30 $\mathrm{mg} / \mathrm{kg}$ linagliptin (Lina 30). The drug doses were selected based on a previous report (17) relevant to the effective doses of linagliptin with regard to glucose metabolism in obese mice. The treatments were administered via oral gavage at a volume of $0.1 \mathrm{~mL} / 10 \mathrm{~g}$ of body weight once daily for 12 weeks. Blood samples from the tail vein were collected to measure blood glucose levels by using a blood glucose measuring device (FreeStyle Freedom; Nipro Co., Ltd., Osaka, Japan). All animals were euthanized under $\mathrm{CO}_{2}$ anesthesia $24 \mathrm{~h}$ after the final drug was administered. The femur and tibia were dissected, and soft tissue was removed.

\subsection{Bone strength analysis}

Bone strength of the femoral mid-diaphysis was evaluated via a three-point bending method using a mechanical testing machine (EZ-S; Shimadzu, Tokyo, Japan). The femur was positioned on two supports placed $10 \mathrm{~mm}$ apart. The bending load was vertically applied to the mid-diaphysis with a crosshead speed of
$1.0 \mathrm{~mm} / \mathrm{min}$ until fracture. The load deformation curves were calculated using operation software (Trapezium $\mathrm{X}$; Shimadzu, Tokyo, Japan), and the maximum load, breaking energy, and stiffness were directly calculated from the load deformation curve.

\subsection{Bone mineral density measurements}

The bone mineral density (BMD) of the whole femur and tibia was measured using quantitative computed tomography (LaTheta LCT-100; Aloka, Tokyo, Japan) with a pixel size of $250 \times 250 \mu \mathrm{m}$ and slice thickness of $1 \mathrm{~mm}$. Cortical, trabecular, and total BMD values were calculated using LaTheta software (ver. 1.31; Aloka, Tokyo, Japan).

\subsection{Serum biochemical markers}

Serum levels of osteocalcin, a bone formation marker, were measured using the osteocalcin EIA kit (Biomedical Technologies Inc., Stoughton, MA, USA). Furthermore, serum levels of tartrate-resistant acid phosphatase-5b (TRAP), a bone resorption marker, were measured using the TRAP assay (Immunodiagnostic Systems Ltd., Tyne \& Wear, UK).

\subsection{Bone histomorphometry}

Non-decalcified specimens from the proximal tibia metaphysis were prepared according to the following method. The tibia was fixed with $70 \%$ ethanol for 7 days, stained with Villanueva Bone Stain (basic fuchsin, fast green, orange G, and azure II; Merck, Darmstadt, Germany) in 70\% methanol for 7 days, and embedded in methyl methacrylate resin. The resin blocks were then sliced to 5 - $\mu \mathrm{m}$ thickness on a microtome (Leica RM2255; Leica Inc., Nussloch, Germany). All bone histomorphometric parameters were measured in the secondary spongiosa region. To exclude the primary spongiosa, the measurement region was $0.11 .2 \mathrm{~mm}$ distal to the lowest point of the growth plate and 0.1 $\mathrm{mm}$ from the lateral cortex.

Bone histomorphometric measurements were performed using a semiautomatic image analyzing system (Histometry RT CAMERA; System Supply, Nagano, Japan) at $\times 400$ magnification. The bone structural parameters evaluated included bone volume per tissue volume (BV/TV), trabecular thickness (Tb.Th), trabecular number (Tb.N), and trabecular separation (Tb.Sp). The bone formation parameters included the osteoid surface per bone surface (OS/ $\mathrm{BS})$, osteoid volume per bone volume (OV/BV), and osteoblast surface per bone surface (Ob.S/BS). Bone resorption parameters included the eroded surface per bone surface (ES/BS), osteoclast surface per bone surface (Oc.S/BS), and osteoclast number per bone surface (N.Oc/BS). Standard bone histomorphometric 
nomenclature, symbols, and units were based on those described in the report of the American Society for Bone and Mineral Research Histomorphometry Nomenclature Committee (18).

\subsection{Statistical analysis}

Data are presented as mean \pm standard error (SE) values. Differences between groups were analyzed by one-way analysis of variance followed by Tukey-Kramer multiple comparisons. $p<0.05$ was considered significant.

\section{Results}

\subsection{Body weight and blood glucose levels}

During the experimental period, body weight and blood glucose levels in the T2DM group were significantly higher than those in the non-DM group (Figure 1). There were no significant differences in mean body weight among the T2DM, Lina 3, and Lina 30 groups during the treatment period of 12 weeks. At 12 weeks after treatment, the mean blood glucose levels in the Lina 3 and Lina 30 groups decreased by approximately $8 \%$ and $22 \%$, respectively, compared with that in the T2DM group. However, intergroup differences were not significant.

\subsection{Bone strength properties}

The following parameters of the femoral mid-diaphysis significantly decreased in the T2DM group compared with those in the non-DM group: maximum load (26\%), breaking energy $(28 \%)$, and stiffness $(22 \%)$ (Table
1). There were no significant differences in the bone strength parameters in the Lina 3 and Lina 30 groups compared to those in the T2DM group.

\subsection{BMD}

Compared to the non-DM group, the T2DM group exhibited significantly decreased cortical BMD (10\%, $14 \%)$, trabecular BMD $(22 \%, 27 \%)$, and total BMD $(19 \%, 22 \%)$ of the whole femur and tibia, respectively
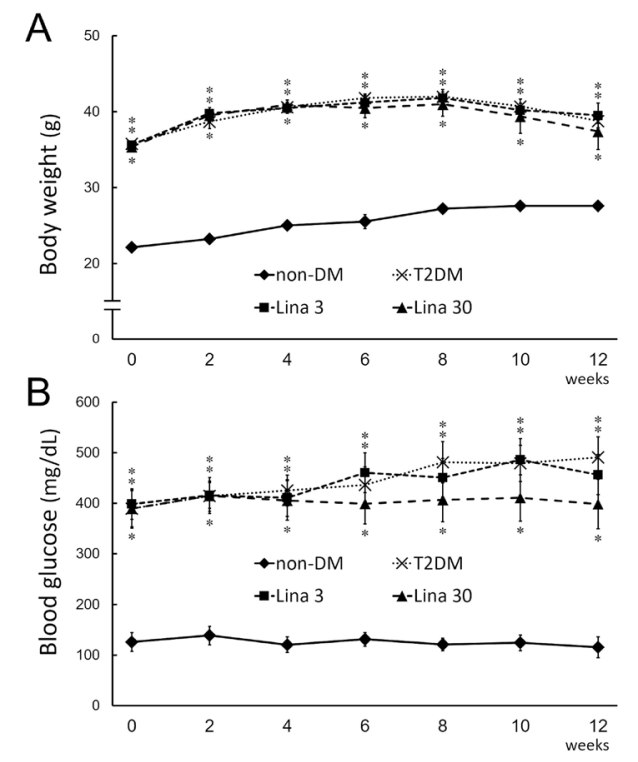

Figure 1. Body weight (A) and blood glucose levels (B). non-DM: non-diabetic mice, T2DM: type 2 diabetic mice treated with vehicle (0.2\% CMC-Na), Lina 3: T2DM mice treated with $3 \mathrm{mg} / \mathrm{kg}$ linagliptin, Lina 30: T2DM mice treated with $30 \mathrm{mg} / \mathrm{kg}$ linagliptin. Data represent the mean $\pm \operatorname{SE}(n=10) .{ }^{*} p<0.05 v s$. the non-DM group.

Table 1. Bone strength properties of the femoral mid-diaphysis

\begin{tabular}{|c|c|c|c|c|}
\hline & non-DM & T2DM & Lina 3 & Lina 30 \\
\hline Maximum load $(\mathrm{N})$ & $18.1 \pm 0.79$ & $13.4 \pm 0.45^{*}$ & $13.9 \pm 0.34^{*}$ & $14.5 \pm 0.41^{*}$ \\
\hline Breaking energy (N.mm) & $4.80 \pm 0.38$ & $3.47 \pm 0.37^{*}$ & $3.68 \pm 0.28^{*}$ & $4.00 \pm 0.25^{*}$ \\
\hline Stiffness (N/mm) & $60.1 \pm 4.51$ & $46.9 \pm 3.31^{*}$ & $48.7 \pm 3.03^{*}$ & $52.2 \pm 3.57^{*}$ \\
\hline
\end{tabular}

non-DM: non-diabetic mice, T2DM: type 2 diabetic mice treated with vehicle $(0.2 \% \mathrm{CMC}-\mathrm{Na})$, Lina $3: \mathrm{T} 2 \mathrm{DM}$ mice treated with $3 \mathrm{mg} / \mathrm{kg}$ linagliptin, Lina 30: T2DM mice treated with $30 \mathrm{mg} / \mathrm{kg}$ linagliptin. Data represent the mean $\pm \mathrm{SE}(n=10) .{ }^{*} p<0.05 \mathrm{vs}$. the non-DM group.

Table 2. BMD of whole femur and tibia

\begin{tabular}{|c|c|c|c|c|}
\hline & non-DM & T2DM & Lina 3 & Lina 30 \\
\hline \multicolumn{5}{|l|}{ Whole femur } \\
\hline Cortical BMD (mg/cm³) & $974 \pm 13.7$ & $871 \pm 12.8^{*}$ & $881 \pm 13.4^{*}$ & $886 \pm 12.3^{*}$ \\
\hline Trabecular BMD $\left(\mathrm{mg} / \mathrm{cm}^{3}\right)$ & $623 \pm 14.9$ & $483 \pm 13.5^{*}$ & $499 \pm 13.9^{*}$ & $511 \pm 15.5^{*}$ \\
\hline Total BMD $\left(\mathrm{mg} / \mathrm{cm}^{3}\right)$ & $917 \pm 13.2$ & $745 \pm 15.4^{*}$ & $754 \pm 13.0^{*}$ & $778 \pm 12.5^{*}$ \\
\hline \multicolumn{5}{|l|}{ Whole tibia } \\
\hline Cortical BMD (mg/cm³) & $998 \pm 10.1$ & $855 \pm 7.86^{*}$ & $860 \pm 11.9^{*}$ & $868 \pm 7.50^{*}$ \\
\hline Trabecular BMD $\left(\mathrm{mg} / \mathrm{cm}^{3}\right)$ & $664 \pm 7.63$ & $487 \pm 16.0^{*}$ & $434 \pm 17.8^{*}$ & $512 \pm 16.1^{*}$ \\
\hline Total BMD $\left(\mathrm{mg} / \mathrm{cm}^{3}\right)$ & $898 \pm 12.9$ & $786 \pm 8.96^{*}$ & $787 \pm 11.6^{*}$ & $799 \pm 14.4^{*}$ \\
\hline
\end{tabular}

BMD: bone mineral density, non-DM: non-diabetic mice, T2DM: type 2 diabetic mice treated with vehicle $(0.2 \% \mathrm{CMC}-\mathrm{Na})$, Lina 3: T2DM mice treated with $3 \mathrm{mg} / \mathrm{kg}$ linagliptin, Lina 30: T2DM mice treated with $30 \mathrm{mg} / \mathrm{kg}$ linagliptin. Data represent the mean $\pm \mathrm{SE}(n=10) .{ }^{*} p<0.05 v s$. the non-DM group. 
(Table 2). On the other hand, no significant differences in BMD were observed after treatment with linagliptin compared to that in the T2DM group.

\subsection{Serum biochemical markers}

Serum osteocalcin levels were significantly lower (45\%) and serum TRAP levels were significantly higher (70\%) in the T2DM group than in the non-DM group (Figure 2). No differences were observed both serum osteocalcin levels and serum TRAP levels in the Lina 3 group compared with the T2DM group. However,

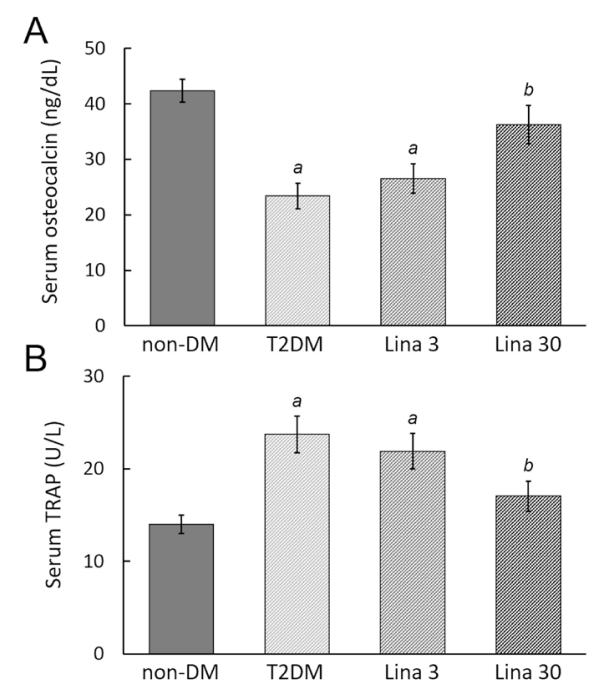

Figure 2. Serum biochemical markers (A: osteocalcin, B: TRAP). non-DM: non-diabetic mice, T2DM: type 2 diabetic mice treated with vehicle $(0.2 \%$ CMC-Na), Lina 3: T2DM mice treated with $3 \mathrm{mg} / \mathrm{kg}$ linagliptin, Lina 30: T2DM mice treated with $30 \mathrm{mg} / \mathrm{kg}$ linagliptin, TRAP: tartrate-resistant acid phosphatase-5b. Data represent the mean $\pm \mathrm{SE}(\mathrm{n}=10) .{ }^{\mathrm{a}} p<0.01 v s$. the non-DM group, ${ }^{\mathrm{b}} p<0.01 v s$. the T2DM group. in the Lina 30 group, serum osteocalcin levels significantly increased (55\%), whereas serum TRAP levels significantly decreased (38\%) compared with the T2DM group values.

\subsection{Bone histomorphometric evaluation}

Bone formation and bone resorption parameters are shown in Figure 3. Compared to those in the nonDM group, in the T2DM mice, the bone formation parameters $\mathrm{OV} / \mathrm{BV}, \mathrm{OS} / \mathrm{BS}$, and Ob.S/BS significantly decreased by approximately 39\%, 59\%, and 79\%, respectively, whereas ES/BS, Oc.S/BS, and N.Oc/BS significantly increased by approximately 94\%, 96\%, and $84 \%$, respectively. However, OV/BV, OS/BS, and Ob.S/BS (44\%, $81 \%$, and $70 \%$, respectively) were significantly increased in the Lina 30 group compared with the T2DM groups. Moreover, ES/BS, Oc.S/BS, and N.Oc/BS $(40 \%, 33 \%$, and $34 \%$, respectively) were significantly decreased in the Lina 30 group compared with those in the T2DM group. Trabecular bone structural parameters are shown in Figure 4. In the T2DM mice showed significantly reduced BV/ TV (55\%), Tb.Th (35\%), and Tb.N (47\%) relative to those in the non-DM group. Furthermore, the values of these bone structural parameters in the Lina 30 group were significantly higher than those in the T2DM group. Figure 5 shows typical microphotographs of the proximal tibia metaphysis using Villanueva Bone Stain. These images confirmed the marked decrease in bone volume, trabecular thickness, and osteoid volume and an increased eroded surface in the T2DM group compared with the non-DM group. In contrast, the Lina 30 group showed markedly increased bone volume, osteoid volume, and trabecular thickness compared with the T2DM group.
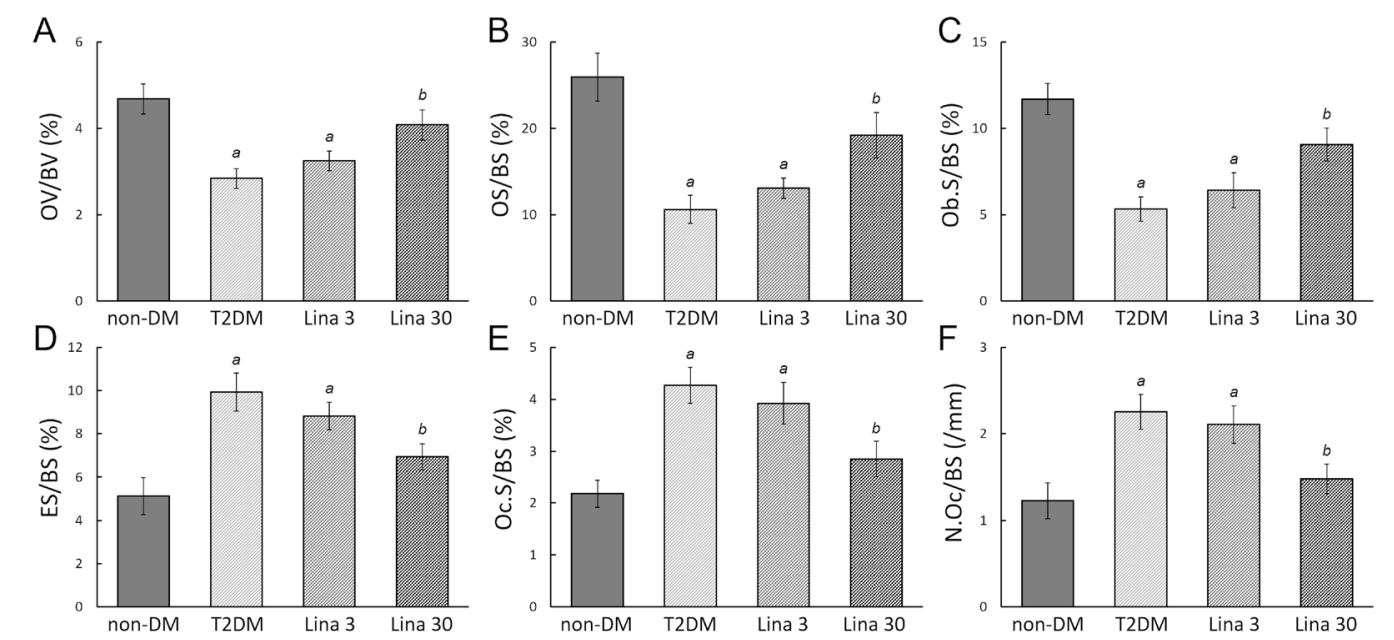

Figure 3. Bone formation parameters (A: osteoid volume [OV/BV], B: osteoid surface [OS/BS], C: osteoblast surface [Ob.S/BS], D: eroded surface [ES/BS], E: osteoclast surface [Oc.S/BS], F: osteoclast number [N.Oc/BS]) according to bone histomorphometry of the proximal tibia metaphysis. non-DM: non-diabetic mice, T2DM: type 2 diabetic mice treated with vehicle $(0.2 \%$ CMC-Na), Lina 3: T2DM mice treated with $3 \mathrm{mg} / \mathrm{kg}$ linagliptin, Lina 30: T2DM mice treated with $30 \mathrm{mg} / \mathrm{kg}$ linagliptin. Data represent the mean $\pm \mathrm{SE}(n=10) .{ }^{\mathrm{a}} p<0.01 \mathrm{vs}$. the non-DM group, ${ }^{\mathrm{b}} p<0.01$ vs. the T2DM group. 


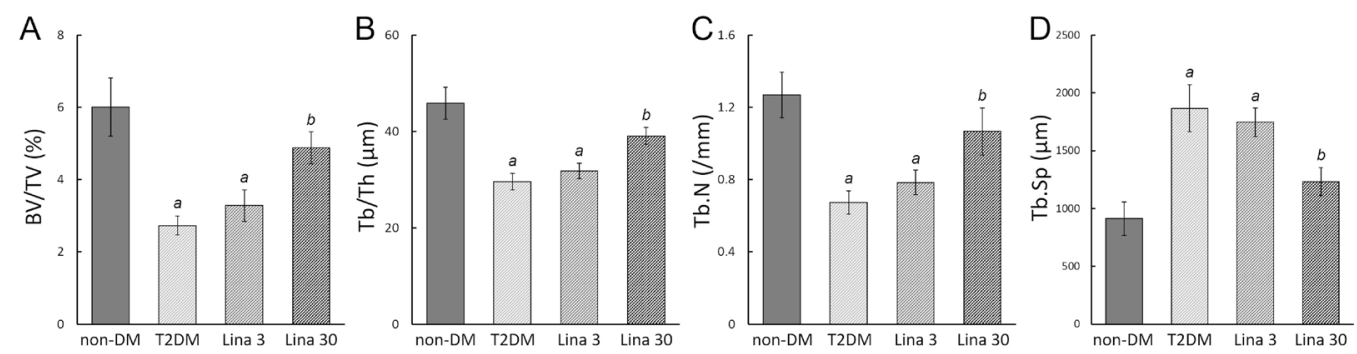

Figure 4. Trabecular bone structural parameters (A: bone volume per tissue volume [BV/TV], B: trabecular thickness [Tb.Th], C: trabecular number [Tb.N], D: trabecular separation [Tb.Sp]) according to the bone histomorphometry of the proximal tibia metaphysis. non-DM: non-diabetic mice, T2DM: type 2 diabetic mice treated with vehicle $(0.2 \%$ CMC-Na), Lina 3: T2DM mice treated with $3 \mathrm{mg} / \mathrm{kg}$ linagliptin, Lina 30: T2DM mice treated with $30 \mathrm{mg} / \mathrm{kg}$ linagliptin. Data represent the mean $\pm \mathrm{SE}(n=10) .{ }^{\mathrm{a}} p<0.05 v s$. the non-DM group, ${ }^{\mathrm{b}} p<0.05$ vs. the T2DM group.

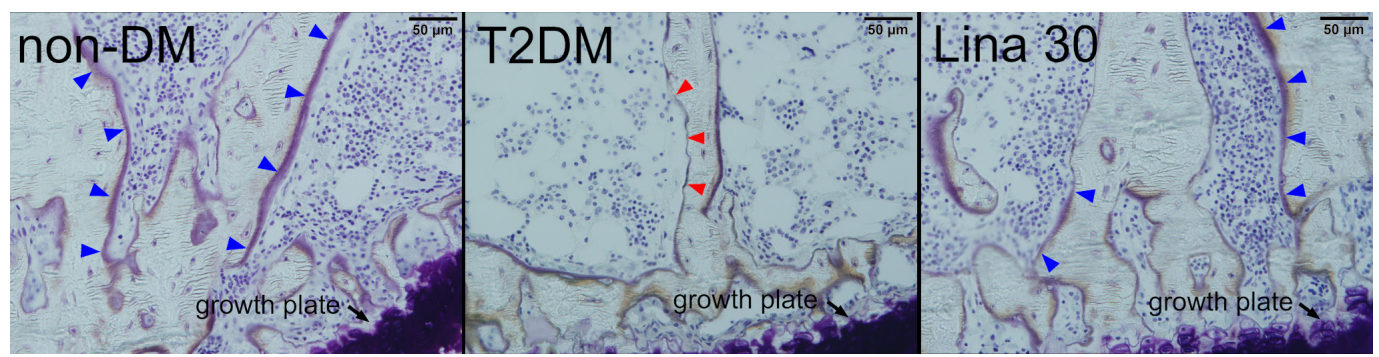

Figure 5. Typical micrographs of slices assessed by bone histomorphometry (Villanueva Bone Stain). The osteoid surface and eroded surface are indicated by blue and red arrows, respectively. non-DM: non-diabetic mice, T2DM: type 2 diabetic mice treated with vehicle ( $0.2 \%$ CMC$\mathrm{Na}$ ), Lina 30: T2DM mice treated with $30 \mathrm{mg} / \mathrm{kg}$ linagliptin.

\section{Discussion}

GIP and GLP-1 are produced by K cells mainly present in the upper small intestine and L cells predominantly present in the lower small intestine, respectively. They are secreted into the blood following dietary intake, and promote insulin secretion from pancreatic $\beta$-cells and suppress postprandial blood glucose elevation (19). A previous study demonstrated that the actions of GIP and GLP-1 are reduced in patients with T2DM compared to those in healthy individuals $(20,21)$. In addition to their roles in glucose metabolism, GIP and GLP-1 have various physiological actions. GIP directly acts on adipocytes, promotes the uptake of glucose and fatty acids, and induces fat accumulation (22). GLP-1 reportedly delays gastric emptying in the gastrointestinal tract (23) and suppresses appetite via the central nervous system (24). In addition to these actions, GIP and GLP-1 may be involved in the regulation of bone metabolism $(15,16)$. DPP-4 inhibitors inactivate the incretin-degrading enzyme DPP-4 and exert antidiabetic effects by increasing the plasma concentrations of both GIP and GLP-1 (25). Several clinical studies have assessed incretin-related drug use and the risk of fracture. A meta-analysis of randomized controlled trials revealed a reduced risk of fracture associated with the use of GLP-1 receptor agonists (26) and DPP-4 inhibitors (27) in the treatment of T2DM patients. Conversely, a retrospective cohort study showed that even long-term use of DPP-4 inhibitors failed to affect the risk of fracture (28). However, the mechanism by which increased incretin action through DPP-4 inhibitors affects bone metabolism remains unclear.

In this study, we used T2DM mice, exhibiting obesity and hyperglycemia induced by marked overeating due to a deficiency of the leptin receptor (29). The T2DM mice in this study exhibited significant hyperglycemia that persisted throughout the 12-week experiment. Further, daily administration of linagliptin reduced the mean blood glucose levels in the T2DM mice in a dosedependent manner, but not significantly. The results of the weak hypoglycemic effect of linagliptin on T2DM mice are consistent with those reported previously in non-diabetic mice (30), streptozotocin-induced diabetic mice $(31,32)$, and T2DM mice $(33,34)$. Importantly, the administration of linagliptin significantly increased serum active GLP-1 concentration in mice without exerting a clear hypoglycemic effect (30,32). Furthermore, the T2DM mice showed significantly decreased bone strength and BMD in the lower limb bones, with a significant decrease in serum osteocalcin levels and a significant increase in serum TRAP levels. These results indicate that bone fragility in T2DM mice is caused by decreased bone formation and increased bone resorption. Linagliptin administration did not significant affect the decreased bone strength and BMD in T2DM mice. However, 
it significantly suppressed both decreased serum osteocalcin levels and increased serum TRAP levels in T2DM mice. Based on biochemical marker analysis, it can be suggested that linagliptin may suppress both decreased bone formation and increased bone resorption induced by T2DM. However, although the biochemical indices of bone metabolism are relatively sensitive indicators of bone turnover, they do not reflect changes in bone density and microstructure (35). Bone histomorphometry is a method used to study histology and quantitatively evaluate the bone remodeling process. Consequently, a combination of bone histomorphometry and biochemical analysis will serve as a powerful tool to assess the changes in bone morphology and metabolism. Therefore, in this study, bone histomorphometry was performed to assess changes in bone remodeling and microstructure attributable to linagliptin administration. T2DM mice showed significantly decreased BV/TV, Tb.Th, and Tb.N and significantly increased Tb.Sp of the proximal tibial trabecular bone, exhibiting rarefaction of trabecular bone owing to the onset of T2DM. In contrast, the deterioration of bone microstructural parameters observed in the T2DM mice improved following linagliptin administration. Furthermore, these mice showed significantly decreased $\mathrm{OV} / \mathrm{BV}$, OS/BS, and Ob.S/BS. Notably, OS/BS and OV/BV are indicators of the ratio of uncalcified bone volume, whereas Ob.S/BS is considered a marker of osteoblast activity (36). Furthermore, the T2DM mice showed significantly increased ES/BS, which indicates the ratio of the bone surface where bone resorption by osteoclasts was induced. This increase in ES/BS was accompanied by an increase in Oc.S/BS and N.Oc/ $\mathrm{BS}$, indicating the ability of osteoclast differentiation. Conversely, linagliptin administration significantly suppressed the decreased OV/BV, OS/BS, and Ob.S/ BS as well as increased ES/BS, Oc.S/BS, and N.Oc/ $\mathrm{BS}$ in T2DM mice. These bone histological findings revealed that linagliptin ameliorates the deterioration of the trabecular bone microstructure by suppressing both decreased bone formation and increased bone resorption caused by T2DM. The mechanisms by which GIP and GLP-1 affect osteoblast and osteoclast functions remain unknown. In a previous study, it was reported that GIP receptors are also present in osteoblasts and that GIP suppresses the apoptosis of osteoblasts (15). In addition, the presence of GIP receptors in osteoclasts has been revealed, and GIP has been shown to directly suppress bone resorption activity increased by the parathyroid hormone (16). In fact, GIP receptor-deficient mice exhibit a significant decrease in the bone formation rate and an increase in the number of osteoclasts (15). In contrast, GIPoverexpressing transgenic mice showed significantly higher BMD, demonstrating an increase in serum osteocalcin levels and a decrease in the levels of the bone resorption marker pyridinoline (37). Furthermore, it has been reported that compared to wild-type mice, GLP-1 receptor-deficient mice exhibit reduced bone strength and decreased BMD, accompanied by suppression of bone formation and enhancement of bone resorption (38). These previous reports and our findings in this study indicate that an increase in GIP and GLP-1 may be responsible for both enhanced bone formation and suppressed bone resorption induced by linagliptin administration. To our knowledge, this is the first study to provide data supporting the phenomenon of linagliptin-induced enhanced bone formation and suppressed bone resorption from the perspective of bone histomorphology.

In conclusion, in this study, we examined the effects of linagliptin on bone fragility in obese T2DM mice. Linagliptin administration suppressed both decreased serum osteocalcin levels and increased serum TRAP levels in T2DM mice. In addition, in terms of histomorphological changes, linagliptin suppressed both decreased bone formation by osteoblasts and increased bone resorption by osteoclasts due to T2DM. Furthermore, linagliptin ameliorated rarefaction in the trabecular bone microstructure in T2DM mice. Based on the above results, this study showed that linagliptin improves trabecular bone microstructure by suppressing both decreased bone formation and increased bone resorption induced by T2DM. These novel findings pertaining to the effects of DPP-4 inhibitors on bone metabolism regulation will be a powerful tool for selecting optimal oral hypoglycemic agents based on the consideration of not only glucose metabolism but also bone fragility in patients with T2DM.

\section{Funding: None.}

Conflict of Interest: The authors have no conflict of interest to disclose.

\section{References}

1. Raisz LG. Physiology and pathophysiology of bone remodeling. Clin Chem. 1999; 45:1353-1358.

2. Rodan GA, Martin TJ. Therapeutic approaches to bone diseases. Science. 2000; 289:1508-1514.

3. Heilmeier U, Patsch JM. Diabetes and bone. Semin Musculoskelet Radiol. 2016; 20:300-304.

4. Hothersall EJ, Livingstone SJ, Looker HC, Ahmed SF, Cleland S, Leese GP, Lindsay RS, McKnight J, Pearson D, Philip S, Wild SH, Colhoun HM. Contemporary risk of hip fracture in type 1 and type 2 diabetes: a national registry study from Scotland. J Bone Miner Res. 2014; 29:1054-1060

5. Janghorbani M, Van Dam RM, Willett WC, Hu FB. Systematic review of type 1 and type 2 diabetes mellitus and risk of fracture. Am J Epidemiol. 2007; 166:495505.

6. Melton LJ 3rd, Leibson CL, Achenbach SJ, Therneau 
TM, Khosla S. Fracture risk in type 2 diabetes: update of a population-based study. J Bone Miner Res. 2008; 23:1334-1342.

7. Weber DR, Haynes K, Leonard MB, Willi SM, Denburg MR. Type 1 diabetes is associated with an increased risk of fracture across the life span: a population-based cohort study using The Health Improvement Network (THIN). Diabetes Care. 2015; 38:1913-1920.

8. Watts NB. Adverse bone effects of medications used to treat non-skeletal disorders. Osteoporos Int. 2017; 28:2741-2746.

9. Kahn SE, Haffner SM, Heise MA, Herman WH, Holman RR, Jones NP, Kravitz BG, Lachin JM, O'Neill MC, Zinman B, Viberti G. Glycemic durability of rosiglitazone, metformin, or glyburide monotherapy. N Engl J Med. 2006; 355:2427-2443.

10. Yaturu S, Bryant B, Jain SK. Thiazolidinedione treatment decreases bone mineral density in type 2 diabetic men. Diabetes Care. 2007; 30:1574-1576.

11. Meier C, Kraenzlin ME, Bodmer M, Jick SS, Jick H, Meier CR. Use of thiazolidinediones and fracture risk. Arch Intern Med. 2008; 168:820-825.

12. Nissen SE, Nicholls SJ, Wolski K, Nesto R, Kupfer $\mathrm{S}$, Perez A, Jure H, De Larochellière R, Staniloae CS, Mavromatis K, Saw J, Hu B, Lincoff AM, Tuzcu EM. Comparison of pioglitazone $v s$ glimepiride on progression of coronary atherosclerosis in patients with type 2 diabetes: the PERISCOPE randomized controlled trial. JAMA. 2008; 299:1561-1573.

13. Lecka-Czernik B, Gubrij I, Moerman EJ, Kajkenova O, Lipschitz DA, Manolagas SC, Jilka RL. Inhibition of Osf2/Cbfa 1 expression and terminal osteoblast differentiation by PPARgamma 2. J Cell Biochem. 1999; 74:357-371.

14. Kanda J, Izumo N, Kobayashi Y, Onodera K, Shimakura T, Yamamoto N, Takahashi HE, Wakabayashi H. Effect of the antidiabetic agent pioglitazone on bone metabolism in rats. J Pharmacol Sci. 2017; 135:22-28.

15. Tsukiyama K, Yamada Y, Yamada C, Harada N, Kawasaki Y, Ogura M, Bessho K, Li M, Amizuka N, Sato M, Udagawa N, Takahashi N, Tanaka K, Oiso Y, Seino Y. Gastric inhibitory polypeptide as an endogenous factor promoting new bone formation after food ingestion. Mol Endocrinol. 2006; 20:1644-1651.

16. Zhong Q, Itokawa T, Sridhar S, Ding KH, Xie D, Kang B, Bollag WB, Bollag RJ, Hamrick M, Insogna K, Isales $\mathrm{CM}$. Effects of glucose-dependent insulinotropic peptide on osteoclast function. Am J Physiol Endocrinol Metab. 2007; 292:E543-E548.

17. Kern M, Klöting N, Niessen HG, Thomas L, Stiller D, Mark M, Klein T, Blüher M. Linagliptin improves insulin sensitivity and hepatic steatosis in diet-induced obesity. PLoS One. 2012; 7:e38744.

18. Dempster DW, Compston JE, Drezner MK, Glorieux FH, Kanis JA, Malluche H, Meunier PJ, Ott SM, Recker RR, Parfitt AM. Standardized nomenclature, symbols, and units for bone histomorphometry: a 2012 update of the report of the ASBMR Histomorphometry Nomenclature Committee. J Bone Miner Res. 2013; 28:2-17.

19. Gautier JF, Choukem SP, Girard J. Physiology of incretins (GIP and GLP-1) and abnormalities in type 2 diabetes. Diabetes Metab. 2008; 34:S65-S72.

20. Nauck M, Stöckmann F, Ebert R, Creutzfeldt W. Reduced incretin effect in type 2 (non-insulin-dependent) diabetes. Diabetologia. 1986; 29:46-52.
21. Holst JJ, Knop FK, Vilsbøll T, Krarup T, Madsbad S. Loss of incretin effect is a specific, important, and early characteristic of type 2 diabetes. Diabetes Care. 2011; 34:S251-S257.

22. Miyawaki K, Yamada Y, Ban N, et al. Inhibition of gastric inhibitory polypeptide signaling prevents obesity. Nat Med. 2002; 8:738-742.

23. Scrocchi LA, Brown TJ, MaClusky N, Brubaker PL, Auerbach AB, Joyner AL, Drucker DJ. Glucose intolerance but normal satiety in mice with a null mutation in the glucagon-like peptide 1 receptor gene. Nat Med. 1996; 2:1254-1258.

24. Turton MD, O'Shea D, Gunn I, Beak SA, Edwards CM, Meeran K, Choi SJ, Taylor GM, Heath MM, Lambert PD, Wilding JP, Smith DM, Ghatei MA, Herbert J, Bloom SR. A role for glucagon-like peptide-1 in the central regulation of feeding. Nature. 1996; 379:69-72.

25. Eto T, Inoue S, Kadowaki T. Effects of once-daily teneligliptin on 24-h blood glucose control and safety in Japanese patients with type 2 diabetes mellitus: a 4-week, randomized, double-blind, placebo-controlled trial. Diabetes Obes Metab. 2012; 14:1040-1046.

26. Su B, Sheng H, Zhang M, Bu L, Yang P, Li L, Li F, Sheng C, Han Y, Qu S, Wang J. Risk of bone fractures associated with glucagon-like peptide-1 receptor agonists' treatment: a meta-analysis of randomized controlled trials. Endocrine. 2015; 48:107-115.

27. Monami M, Dicembrini I, Antenore A, Mannucci E. Dipeptidyl peptidase-4 inhibitors and bone fractures: a meta-analysis of randomized clinical trials. Diabetes Care. 2011; 34:2474-2476.

28. Driessen JH, van den Bergh JP, van Onzenoort HA, Henry RM, Leufkens HG, de Vries F. Long-term use of dipeptidyl peptidase-4 inhibitors and risk of fracture: A retrospective population-based cohort study. Diabetes Obes Metab. 2017; 19:421-428.

29. Guest PC, Rahmoune H. Characterization of the $d b / d b$ mouse model of type 2 diabetes. Methods Mol Biol. 2019; 1916:195-201.

30. Terawaki Y, Nomiyama T, Kawanami T, Hamaguchi Y, Takahashi H, Tanaka T, Murase K, Nagaishi R, Tanabe M, Yanase T. Dipeptidyl peptidase-4 inhibitor linagliptin attenuates neointima formation after vascular injury. Cardiovasc Diabetol. 2014; 13:154.

31. Ide M, Sonoda N, Inoue T, Kimura S, Minami Y, Makimura H, Hayashida E, Hyodo F, Yamato M, Takayanagi R, Inoguchi T. The dipeptidyl peptidase-4 inhibitor, linagliptin, improves cognitive impairment in streptozotocin-induced diabetic mice by inhibiting oxidative stress and microglial activation. PLoS One. 2020; 15:e0228750.

32. Zhang Y, Fava GE, Wu M, Htun W, Klein T, Fonseca VA, Wu H. Effects of linagliptin on pancreatic $\alpha$ cells of type 1 diabetic mice. J Endocr Soc. 2017; 1:1224-1234.

33. Takahashi H, Nomiyama T, Terawaki Y, Horikawa T, Kawanami T, Hamaguchi Y, Tanaka T, Motonaga R, Fukuda T, Tanabe M, Yanase T. Combined treatment with DPP-4 inhibitor linagliptin and SGLT2 inhibitor empagliflozin attenuates neointima formation after vascular injury in diabetic mice. Biochem Biophys Rep. 2019; 18:100640.

34. Michurina SV, Ishenko IJ, Klimontov VV, Archipov SA, Myakina NE, Cherepanova MA, Zavjalov EL, Koncevaya GV, Konenkov VI. Linagliptin alleviates fatty liver disease in diabetic $d b / d b$ mice. World J Diabetes. 2016; 7:534-546. 
35. Vidal B, Pinto A, Galvão MJ, Santos AR, Rodrigues A, Cascão R, Abdulghani S, Caetano-Lopes J, Ferreira A, Fonseca JE, Canhao H. Bone histomorphometry revisited. Acta Reumatol Port. 2012; 37:294-300.

36. Recker RR, Kimmel DB, Dempster D, Weinstein RS, Wronski TJ, Burr DB. Issues in modern bone histomorphometry. Bone. 2011; 49:955-964.

37. Xie D, Zhong Q, Ding KH, Cheng H, Williams S, Correa D, Bollag WB, Bollag RJ, Insogna K, Troiano N, Coady C, Hamrick M, Isales CM. Glucose-dependent insulinotropic peptide-overexpressing transgenic mice have increased bone mass. Bone. 2007; 40:1352-1360.

38. Yamada C, Yamada Y, Tsukiyama K, Yamada K, Udagawa N, Takahashi N, Tanaka K, Drucker DJ, Seino Y, Inagaki N. The murine glucagon-like peptide-1 receptor is essential for control of bone resorption. Endocrinology. 2008; 149:574-549.

Received August 26, 2020; Revised October 1, 2020; Accepted October 18, 2020

*Address correspondence to:

Hiroyuki Wakabayashi, Department of Clinical Pharmacotherapy, Faculty of Pharmaceutical Sciences, Niigata University of Pharmacy and Applied Life Sciences, 265-1 Higashijima, Akiha-ku, Niigata 956-8603, Japan.

E-mail: waka@nupals.ac.jp

Released online in J-STAGE as advance publication October 29, 2020. 